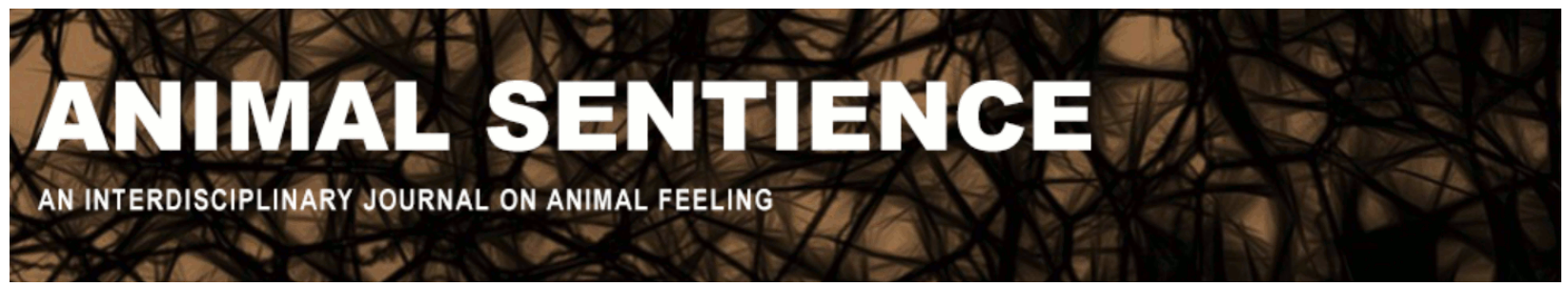

Morand, Serge (2020) New approach to health and the environment to avoid future pandemics. Animal Sentience 30(14)

DOI: $10.51291 / 2377-7478.1644$

Date of submission: 2020-09-09

Date of acceptance: 2020-09-09

(c)

This article has appeared in the journal Animal

Sentience, a peer-reviewed journal on animal

cognition and feeling. It has been made open access,

free for all, by WellBeing International and deposited

in the WBI Studies Repository. For more information,

please contact

wbisr-info@wellbeingintl.org.

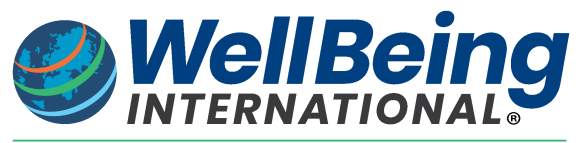

SOLUTIONS FOR PEOPLE, ANIMALS AND ENVIRONMENT 


\title{
New approach to health and the environment to avoid future pandemics
}

\author{
Commentary on Wiebers \& Feigin on Covid Crisis
}

\section{Serge Morand}

CNRS-CIRAD-Montpellier University \& Faculty Tropical Medicine, Mahidol University

\begin{abstract}
This commentary expands Wiebers \& Feigin's target article by pinpointing how declining wildlife, expanding livestock and globalisation contribute to the increase in epidemics of zoonotic diseases, the COVID-19 crisis and future health crises. Epidemics and the emergence of zoonoses are manifestations of dysfunctional links with animals, both wild and domestic, requiring a new approach to health and the environment.
\end{abstract}

Serge Morand, senior researcher at CNRS and Cirad in France, invited Professor at the Faculty of Tropical Medicine (Mahidol University, Bangkok), is a health ecologist investigating infectious diseases at the interface between wildlife and livestock in changing socio-ecosystems of Southeast Asia. Website

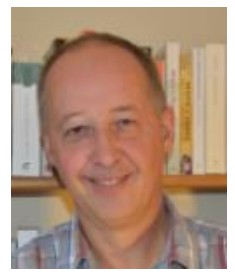

\section{An epidemic of epidemics}

Epidemiological data show that epidemics of zoonotic diseases, some of them originating from wildlife, are clearly increasing (Morand 2020). There are more epidemics, and they are shared among a growing number of countries. Epidemics are increasingly becoming pandemics. Globalisation and international trade favour the global spread of infectious diseases while at the same time rendering countries less and less resilient to health crises. The great acceleration of epidemics is a consequence of the great acceleration of trade. The number of air transport passengers has increased by 1,300\% since the year 1960, with more than 4 billion passengers transported in 2019 (Morand \& Walther 2020).

A major pandemic was foreseeable. The World Health Organization (WHO) called it "disease $X "$ and listed several potential infectious agents, but without exploring closely the socioecological conditions of their potential to emerge (Simpson et al. 2020). Important programs, endowed with considerable resources, have been put in place. The current pandemic cruelly highlights the failure of both the preparedness strategies and the predictions for emerging diseases (a failure already noted during the Ebola epidemic in West Africa). Preparedness through bio-surveillance and biosecurity measures or by cataloguing all the viruses of wild animals, while important, are clearly not enough to prevent the emergence of zoonoses or to reduce the conditions conducive to pandemics (Broom 2020; Cao 2020).

\section{Biodiversity crisis and zoonotic epidemics}

The number of zoonotic epidemics is globally correlated with the biodiversity crisis. Countries that are rich in threatened biodiversity are also the countries with a high number of reported epidemics. The causal factors underlying this are to be found in the increase in livestock, deforestation, and the loss of traditionally managed habitats for the benefit of commercial plantations (Roche et al. 2020).

The analysis of global data across time shows that the increase in livestock is a major cause of both the decline in biodiversity and the increase in zoonotic epidemics (Morand 2020; Schuck- 
Palm 2020). In 1960, there were just under a billion cattle globally. Their number exceeded 1.6 billion in 2016. At the same time, the number of pigs worldwide grew from 500 million to 1.5 billion, and the number of chickens from 5 billion to 22 billion (not counting laying hens). Livestock now have a biomass greater than that of all humans, and there are more chickens than all wild birds combined.

The biodiversity crisis is more than a programmed extinction of wild species; it is a major modification of the interspecific interactions essential for the proper functioning of ecosystems and the quality of ecosystem services. The simplification of habitats through industrial agriculture and farming decreases the ecological regulation of reservoir animals, favouring the spill-over of microbial agents circulating in wildlife to domestic animals and humans. The ecosystem service regulating disease transmission is neutralised. Habitats whose diversity has been simplified lose their ecological resilience as well as their resilience to epidemics.

\section{Strengthening our understanding of health emergencies and crises}

The experience of Covid-19 shows us that the management of the current health emergency is being done without an understanding of the processes that led from its onset to the global health crisis. The ecology of its emergence is reduced to a story about a pangolin sold in a market in a large Chinese city. To understand the processes by which zoonoses emerge globally we need to deepen and strenghten our analysis, distinguishing three levels: biological, epidemiological and political.

The biological level. The origin of an infectious agent and its reservoir is biological. In the case of SARS-CoV2, it is a beta-coronavirus with an insectivorous bat species as reservoir, and potentially a pangolin as an intermediate mammalian host. Research at this level of analysis ranges from virology to immunology to infectious diseases. This research makes it possible to complete the cataloguing of potentially emerging viruses and their adaptation to host changes in order to develop new diagnostic and treatment tools.

The epidemiological level. The second level of analysis, the epidemiological one, investigates the mode of transmission of the infectious agent between animals, and between animals and humans. The transmission takes place in an ecological, social and economic context. This context can be that of the biodiversity crisis, the trafficking of wild animals, deforestation, the increase in livestock, and the globalisation of trade and tourism. To understand it requires, understanding the local conditions of interspecific transmission between the bat and the intermediate host, followed by expanding human-to-human transmission. In other words, it requires understanding how a virus that circulated quietly in bat populations somewhere in Asia could end up a few months later in all human populations of the planet.

The political level. The third level of analysis, the political one, concerns the management of the health crisis. This involves the perception of the epidemic by human population, the health profession and decision-makers. Having acquired the status of a health crisis, the current epidemic is generating a (bio)political response with the implementation of quarantines, containment, movement limitations, traceability techniques, and the development of screening tests and treatment modalities. These crisis management measures have implications for emerging from the crisis, learning lessons from it, and being prepared for potential future health crises. Unfortunately, each health crisis has led only to strengthening biosecurity measures rather than to addressing the social and ecological causes of the emergence and the spread of epidemics themselves (Gidon 2020). 


\section{Identify and overcome disciplinary and sectoral boundaries}

Epidemics and the emergence of zoonoses are symptoms of dysfunctional links with animals, both wild and domestic. Little consideration is being given to the health of ecosystems themselves. Health measures are not well implemented in the policies advocated by WHO. Intersectoral dialogue and action during health crises is lacking.

Since 2008, the "One Health" approach supported by the tripartite collaboration agreement between WHO , OIE (World Organisation for Animal Health) and FAO (Food and Agriculture Organisation of the United Nations) has attempted to fight against the threats from zoonotic diseases. It is clear that an essential pillar supporting the environmental dimension and contributes to health, such as biodiversity, is missing. The United Nations Environment Program (UNEP), the world's leading authority on the environment, is able to provide this dimension. UNEP already hosts the secretariats of many international environmental conventions, such as the Convention on International Trade in Endangered Species of Wild Fauna and Flora ( $\underline{\mathrm{CITES}})$, the Convention on Biological Diversity $(\underline{\mathrm{CBD}})$, the Convention on Migratory Species and the United Nations Convention to Combat Desertification (UNCCD). Through its mandate of international environmental governance, UNEP appears to be able to anchor a new approach to the challenges of a healthy planet for all.

UNESCO, with its mandates in education and science, carries the Man and the Biosphere program based on the ecosystem approach used in biosphere reserves. UNESCO offers a unique opportunity to address health issues within the framework of local governance reconciling the conservation of biodiversity with its sustainable use.

A new approach to health and the environment -- whether One Health, eco-health, planetary health or global health (Fawcett 2020; Fox 2020) -- requires that disciplinary and sectoral boundaries (medicine, veterinary medicine, ecology, economics, polity) be clearly identified so as to develop collaborative and jointly constructed health policies involving communities of citizens, scientists, public health and administrative bodies within the framework of a new social-ecological health governance. Our ability to avoid future health and social crises linked to zoonoses will depend on our implementing this new health and environmental approach.

\section{References}

Broom, Donald M (2020) The necessity of human attitude change and methods of avoiding pandemics. Animal Sentience 30(7)

Cao, Deborah (2020) Global risks of intensive animal farming and the wildlife trade. Animal Sentience 30(2)

Eshel, Gidon (2020) Pandemic leadership failures and public health. Animal Sentience 30(3)

Fawcett, Anne (2020) One Welfare, the role of health professionals, and climate change. Animal Sentience 30(9)

Fox, Michael W. (2020) One planet, one health. Animal Sentience 30(6)

Morand, Serge (2020) Emerging diseases, livestock expansion and biodiversity loss are positively related at global scale. Biological Conservation 248: 108707 
Morand, Serge \& Walther, Bruno A. (2020) The accelerated infectious disease risk in the Anthropocene: more outbreaks and wider global spread. bioRxiv https://doi.org/10.1101/2020.04.20.049866.

Roche B., Garchitorena A., Guégan J.-F., Arnal A., Roiz D., Morand S., Zambrana-Torrelio C., Suzán G., Daszak P. (2020) Was the COVID-19 pandemic avoidable? A call for a "solution-based" approach in pathogen evolutionary ecology to prevent future outbreaks. Ecology Letters https://doi.org/10.1111/ele.13586.

Schuck-Paim, Cynthia (2020) Intensive animal farming conditions are a major threat to global health. Animal Sentience 30(8)

Simpson Shmona, Michael C Kaufmann, Vitaly Glozman \& Ajoy Chakrabarti (2020) Disease X: accelerating the development of medical countermeasures for the next pandemic. Lancet Infectious Diseases 20: e108-15

Wiebers, David \& Feigin, Valery (2020) What the COVID-19 crisis is telling humanity. Animal Sentience 30(1) 